\title{
ESTUDO DE CASO: PROJETO DE UM TANQUE DE TESTE (DISPOSITIVO) PARA ENSAIOS DE VIBRAÇÃO DE BOMBAS DE COMBUSTÍVEIS
}

\author{
Marcelo Leandro dos $\operatorname{Santos}^{1}$, André Morais Ferreira ${ }^{1}$, Dalton de Paula Cavalcanti ${ }^{1}$ e Marcos \\ Paulo Del Passo ${ }^{1}$ \\ ${ }^{1}$ Robert Bosch Ltda. \\ E-mails: marcelo.santos2@br.bosch.com, andremorais.ferreira@br.bosch.com, \\ dalton.cavalcanti@br.bosch.com, marcos.passo@br.bosch.com
}

\section{RESUMO}

Este artigo apresenta um estudo de caso de um projeto de tanque (dispositivo) para ensaios de vibração de bombas de combustíveis. Os modos de vibração do tanque são obtidos através da Análise de Elementos Finitos para aperfeiçoar seu projeto estrutural considerando a faixa de frequência de teste. Após a construção do tanque, uma pesquisa de ressonância é realizada para validar o modelo físico.

\section{INTRODUÇÃO}

Os ensaios de vibração estão presentes em praticamente todas as homologações de novos produtos automotivos. Eles são necessários para comprovar a integridade estrutural do produto durante toda sua vida útil quando submetido às vibrações do ambiente onde se encontra (motor, chassi, suspensão, etc.).

O projeto de dispositivos de teste para ensaios de vibração requer uma atenção especial para que a ressonância do dispositivo não interfira na vibração transmitida para a amostra sob teste. Cuidados devem ser tomados para que as frequências de ressonância do dispositivo estejam acima da faixa de frequência de teste. A simulação por elementos finitos (FEA) é bastante utilizada atualmente na indústria para projetos de dispositivos complexos a fim de reduzir custos com retrabalhos. Através dos resultados obtidos, o projeto do dispositivo pode ser modificado em termos de rigidez e massa para que as frequências de ressonância não influenciem os resultados do teste.

\section{OBJETIVO}

O objetivo do projeto é a construção de um tanque de teste para ensaios de vibração de bombas de combustível sem que o dispositivo interfira na vibração de excitação das bombas, ou seja, que a vibração na base interna de fixação das bombas seja igual à vibração da mesa do shaker. 
A condição de teste solicitada é a seguinte:

Tabela 1 - Parâmetros do teste de vibração com varredura senoidal

\begin{tabular}{|c|c|}
\hline Tipo de ensaio & Varredura Senoidal \\
\hline Frequência & 50 a $500 \mathrm{~Hz}$ \\
\hline Aceleração & $150 \mathrm{~m} / \mathrm{s}^{\mathbf{2}}$ \\
\hline Tipo de varredura & Logarítmica \\
\hline Velocidade de varredura & 1 oitava por minuto \\
\hline Duração & 20h por direção \\
\hline
\end{tabular}

\section{SISTEMA PARA ENSAIO DE VIBRAÇÃO}

Um sistema completo para ensaios de vibração é mostrado na figura 1. Tal sistema é composto por: shaker, amplificador de potência, unidade de refrigeração, unidade de campo, unidade sob teste, acelerômetros, amplificador de carga (no caso de acelerômetros de carga) e sistema de controle (hardware e software).

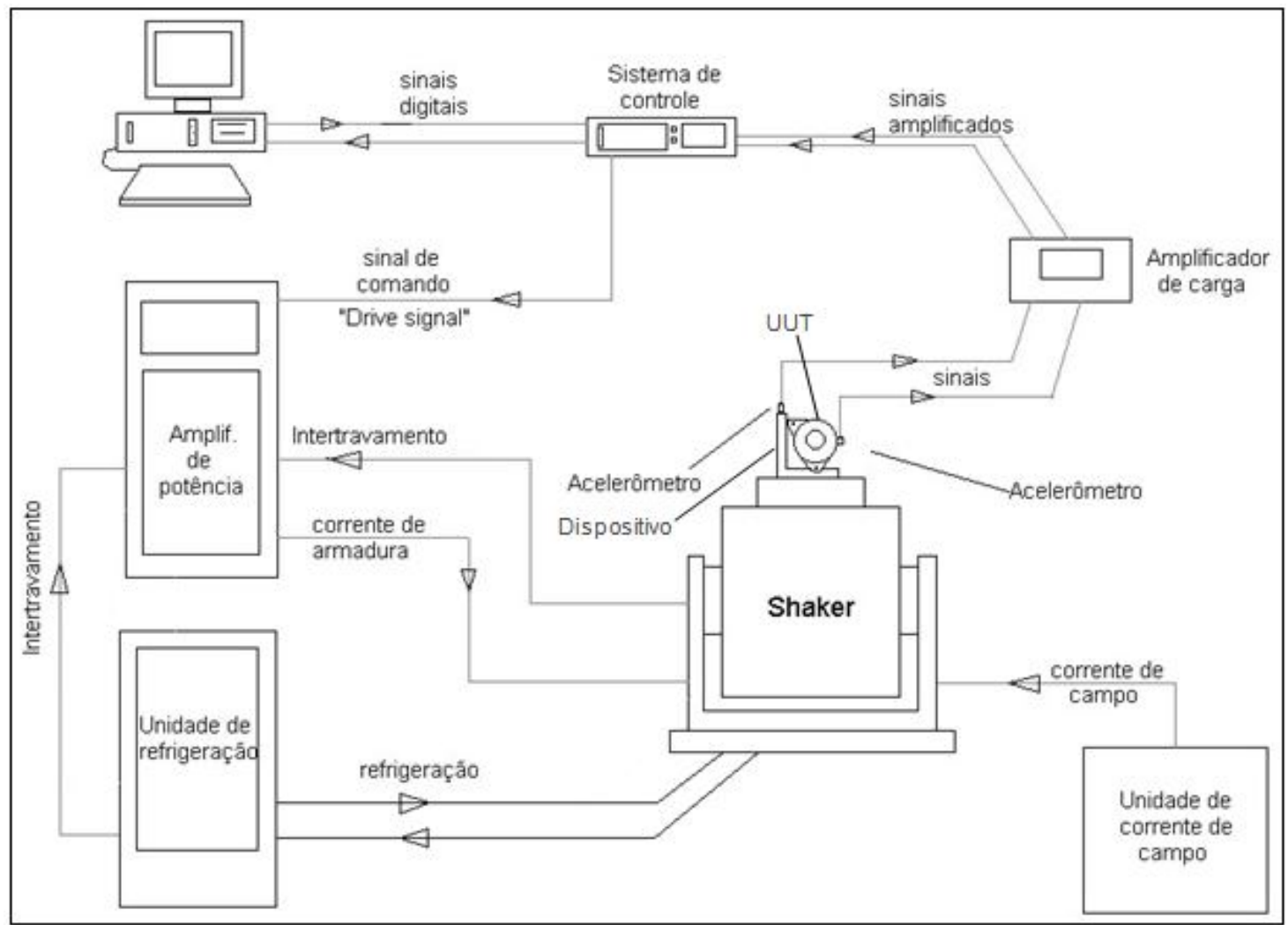

Figura 1 - Sistema completo para ensaio de vibração

\subsection{SHAKER}

O Shaker é o equipamento que produz a vibração. Possui tamanhos variados podendo ser hidráulico ou eletrodinâmico. Este último é capaz de alcançar frequências mais elevadas (até $3 \mathrm{kHz}$ ) e geralmente é o mais utilizado nas indústrias. 
O modelo eletrodinâmico necessita ser refrigerado à água ou ar. Seu princípio de funcionamento é similar ao de um alto falante. Uma corrente contínua circula pela bobina de campo gerando um campo magnético fixo. Uma corrente alternada (de acordo com o tipo de teste) circula pela bobina da armadura gerando um campo magnético alternado. A interação magnética entre os dois campos faz com que a armadura (peça móvel) se desloque para cima e para baixo gerando a vibração.

\subsection{UUT (UNIT UNDER TEST)}

A unidade sob teste nada mais é do que a amostra de teste. É o componente que se deseja avaliar durante o ensaio de vibração.

\subsection{SISTEMA DE CONTROLE}

O sistema de controle é constituído por um hardware e software conforme abaixo:

- Hardware: conjunto de canais de entrada para medição da vibração através dos acelerômetros e canal de saída para acionamento do shaker;

- Software: programa que permite o setup dos parâmetros do teste, acompanhamento do teste e análise de sinais.

\subsection{ACELERÔMETROS}

Os acelerômetros são os transdutores que convertem a aceleração em uma grandeza elétrica da ordem de $\mathrm{pC}$ (pico-Coulombs) no caso de transdutores de carga ou $\mathrm{mV}$ (mili-Volts) no caso de transdutores IPE. Através deles é estabelecida a malha fechada para o controle da aceleração que se deseja aplicar.

\subsection{DISPOSITIVO}

O dispositivo é o componente que faz a interface entre a mesa de vibração e a amostra de teste. Ele permite a fixação da amostra conforme aplicação em veículo e é responsável por transmitir a vibração da mesa para a amostra sem alterar os níveis de aceleração ao longo de todo o range de frequência de teste. Este item é o foco principal desse artigo.

\section{OBTENÇÃO DAS FREQUÊNCIAS NATURAIS ATRAVÉS DA TRANSMISSIBILIDADE}

Um método direto para encontrar ressonâncias é medir a função transferência entre o sinal de resposta da amostra (aceleração, velocidade ou deslocamento) e o sinal de força de excitação. A ressonância será o pico da curva da função transferência. Infelizmente esse método é inviável na operação de controle do shaker porque a medição da força não é fácil de ser obtida (em caso de shakers grandes voltados para ensaios de durabilidade). Ao invés disso, a transmissibilidade é normalmente usada para encontrar a ressonância.

De acordo com Harris [1], a frequência de ressonância é definida como a frequência na qual a resposta é máxima quando comparada à excitação. 


\section{PROJETO DO TANQUE}

Com base na necessidade de se testar o maior número possível de bombas e de acordo com o espaço disponível para fixação na mesa de vibração (440 mm de diâmetro), definiu-se um tanque no formato cilíndrico, o que permite simetria dos modos, e internamente projetou-se uma base para fixação de quatro bombas com seus respectivos pré-filtros.

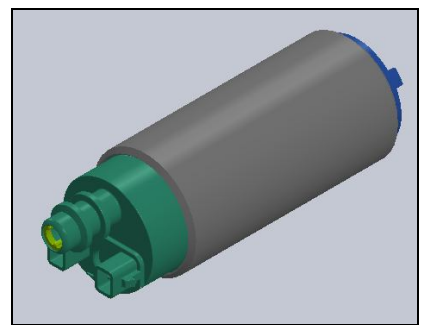

Figura 2 - Modelo da bomba a ser testada (UUT)

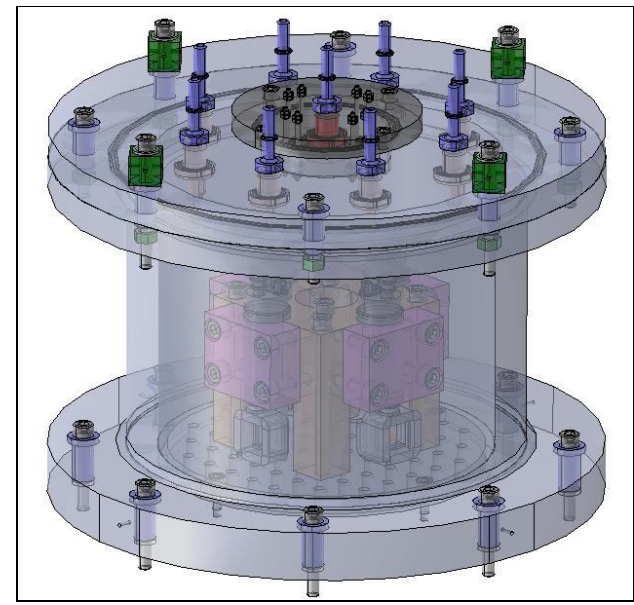

Figura 3 - Modelo do tanque de teste (dispositivo)

Com a necessidade de se testar as bombas em funcionamento, na tampa do tanque foram adaptadas nove conexões hidráulicas sendo uma saída e um retorno para cada bomba e um "respiro" no centro.

Visando a redução de massa e aumento da rigidez do tanque para que a frequência do $1^{\circ}$ modo de vibração tendesse a um valor superior à frequência máxima do teste $(500 \mathrm{~Hz})$, optou-se pela construção do tanque em alumínio, segundo material mais utilizado para este tipo de finalidade, sendo o magnésio (ou ligas de magnésio) o primeiro. O inconveniente do magnésio é o risco de ignição em contato com fluídos à base de água durante a usinagem e, por esse motivo, muitos fornecedores não trabalham com esse material.

Tabela 2 - Comparativo dos principais materiais usados na construção de dispositivos de vibração

\begin{tabular}{|c|c|c|c|}
\hline Material & Densidade & Módulo de Elasticidade & Coeficiente de Poison \\
\hline Aço & $7,85 \mathrm{~g} / \mathrm{cm}^{3}$ & $200 \mathrm{a} 207 \mathrm{GPa}$ & 0,30 \\
\hline Alumínio & $2,71 \mathrm{~g} / \mathrm{cm}^{3}$ & $69 \mathrm{a} 72,4 \mathrm{GPa}$ & 0,33 \\
\hline Magnésio & $1,74 \mathrm{~g} / \mathrm{cm}^{3}$ & $45 \mathrm{GPa}$ & 0,35 \\
\hline
\end{tabular}




\section{FEA}

Uma análise pelo Método de Elementos Finitos (FEM) foi realizada através dos softwares ANSYS e ABAQUS para levantamento das frequências naturais.

Um modelo de simulação simplificado (conforme figura 3) foi utilizado visando reduzir cálculos e tempo de processamento. Os componentes que não afetavam a rigidez do tanque foram removidos. As bombas e filtros foram substituídos por pontos de massa concentrada (170g) localizados no centro de gravidade de cada bomba. O fluído de teste foi desconsiderado e os contatos entre componentes foram modelados como "tie constraints".

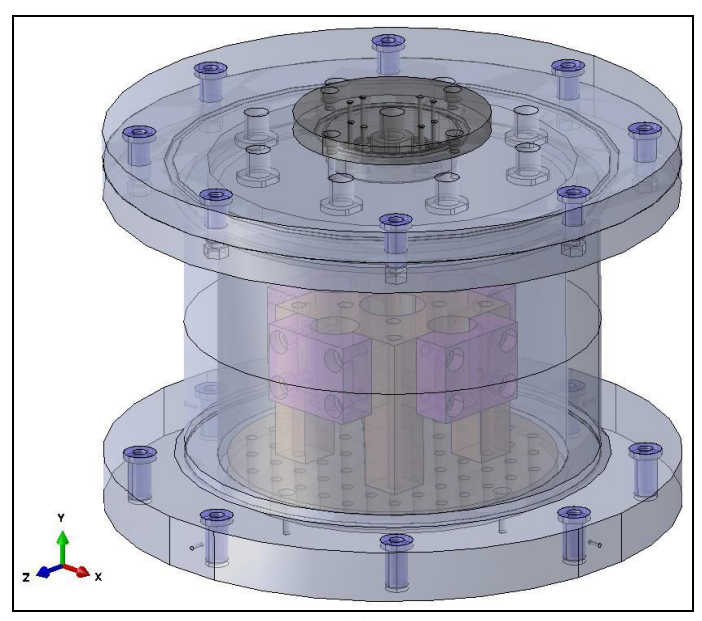

Figura 4 - Modelo simplificado do tanque de teste

Os componentes do tanque são mostrados na figura 5 e as propriedades dos materiais utilizados são apresentadas na tabela 3 .

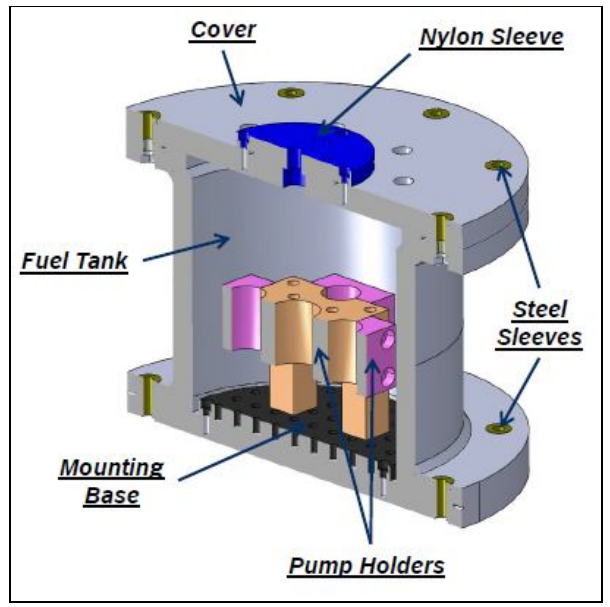

Figura 5 - Componentes do tanque de teste 
Tabela 3 - Propriedade dos materiais utilizados na simulação

\begin{tabular}{|c|c|c|c|c|c|}
\hline \multirow{2}{*}{ Part } & Material & $\begin{array}{c}\text { Density } \\
{\left[\mathbf{g} / \mathbf{c m}^{\mathbf{3}}\right]}\end{array}$ & $\begin{array}{c}\text { Young's } \\
\text { Modulus } \\
{[\mathbf{G P a}]}\end{array}$ & $\begin{array}{c}\text { Poisson's } \\
\text { Ratio }\end{array}$ & $\begin{array}{c}\text { Structural } \\
\text { Damping }\end{array}$ \\
\cline { 1 - 2 } Tank & Aluminum & 2,71 & 68,9 & 0,33 & 0,06 \\
\hline Cover & 6351-T6 & & 207 & 0,30 & 0,06 \\
\hline Pump Holders & Steel SAE1020 & 7,85 & 193 & 0,30 & 0,06 \\
\hline Steel Sleeves & Stainless 304 & 8,0 & 3,1 & 0,38 & 0,06 \\
\hline Nylon Sleeve & Poluacetal w/o fibre & 1,42 & & & \\
\hline
\end{tabular}

Obteve-se como resultado as seguintes frequências naturais:

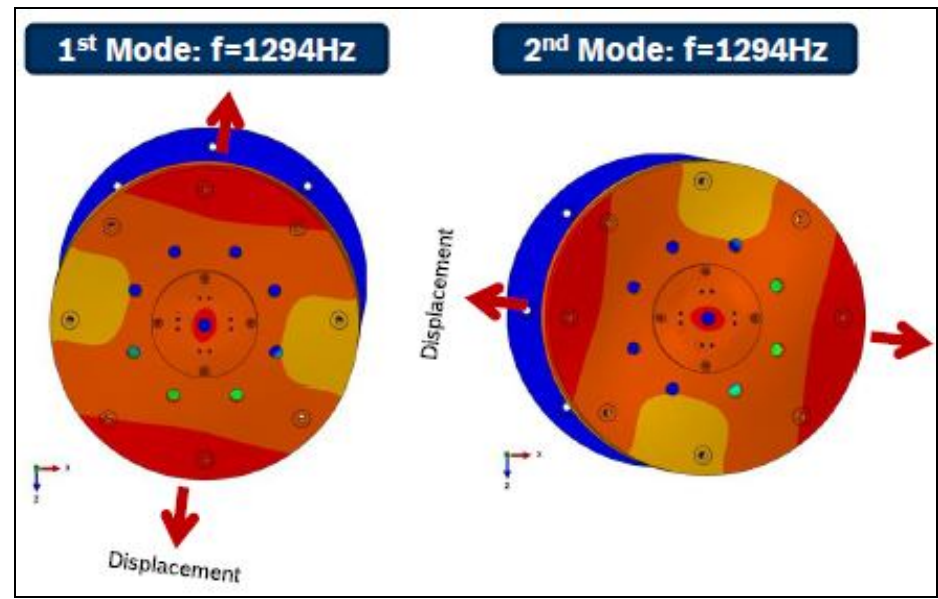

Figura 6 - Frequências naturais do $1^{\circ}$ e $2^{\circ} \operatorname{modo}$

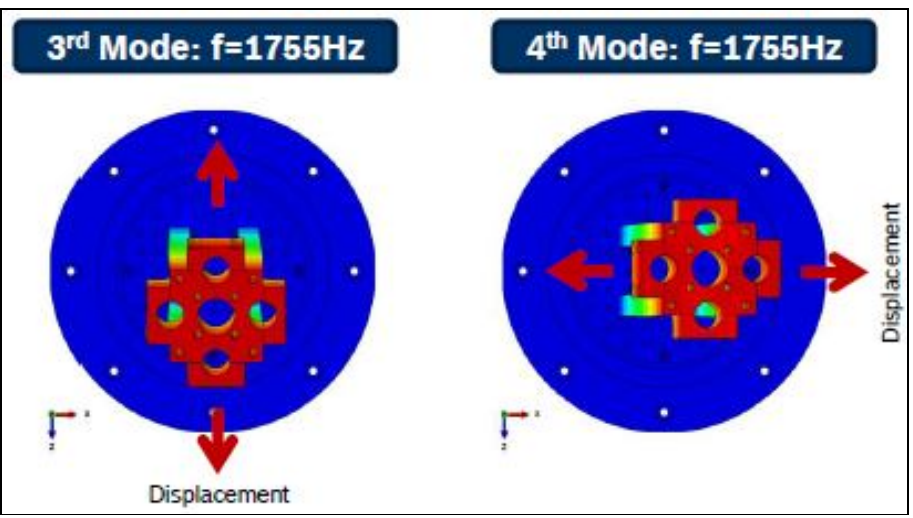

Figura 7 - Frequências naturais do $3^{\circ}$ e $4^{\circ}$ modo

Adicionalmente foram levantadas, através da análise harmônica, as acelerações em pontos estratégicos quando aplicada na base uma aceleração constante de $150 \mathrm{~m} / \mathrm{s}^{2}$ variando de 50 a $2000 \mathrm{~Hz}$. 


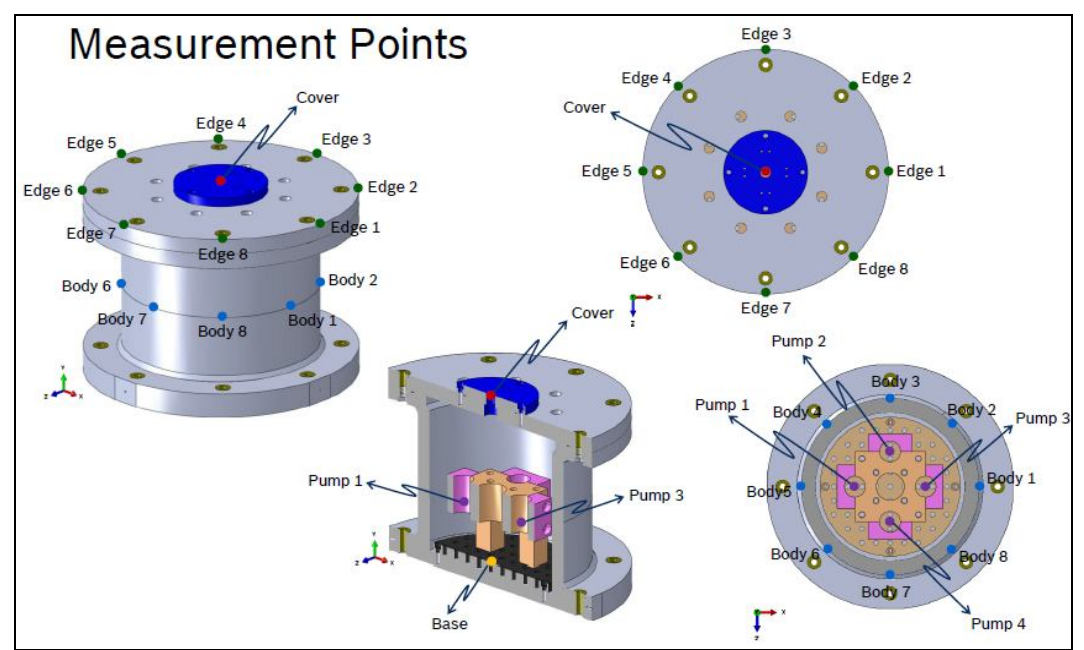

Figura 8 - Pontos de interesse

Obtiveram-se os seguintes níveis de aceleração:

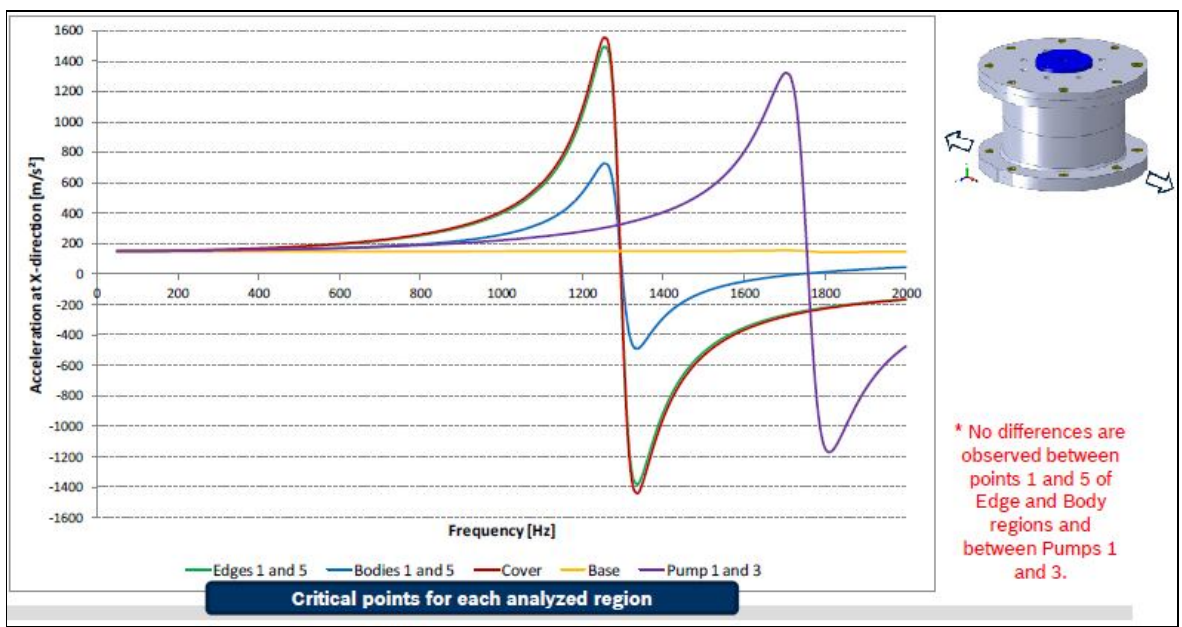

Figura 9 - Níveis de aceleração na direção $X$

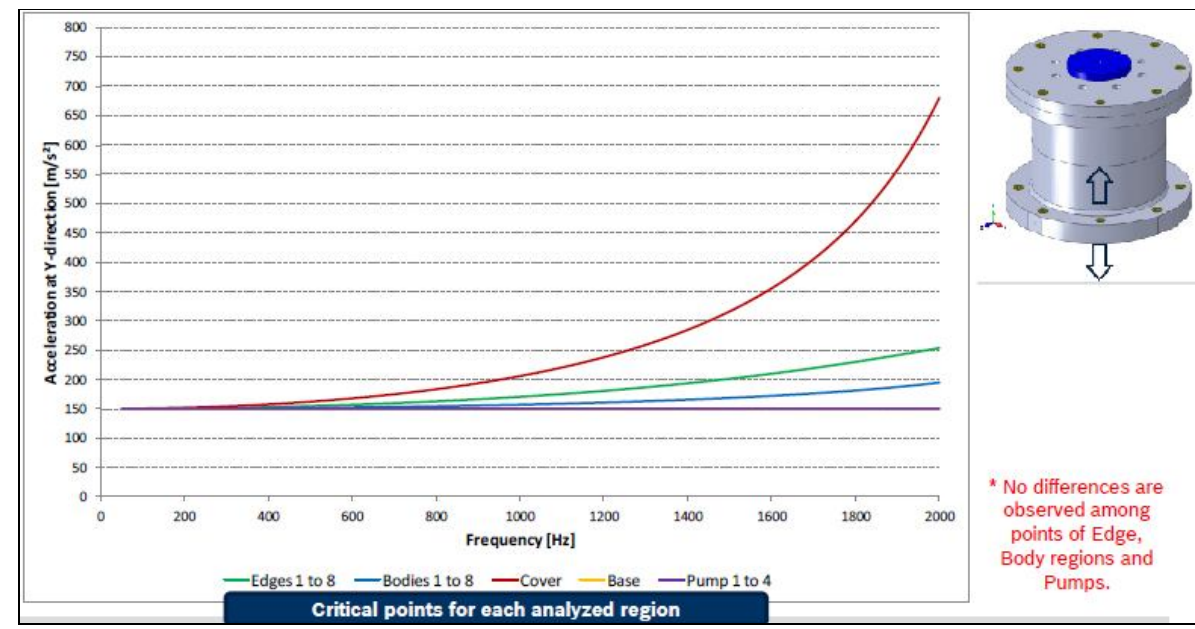

Figura 10 - Níveis de aceleração na direção $Y$ 


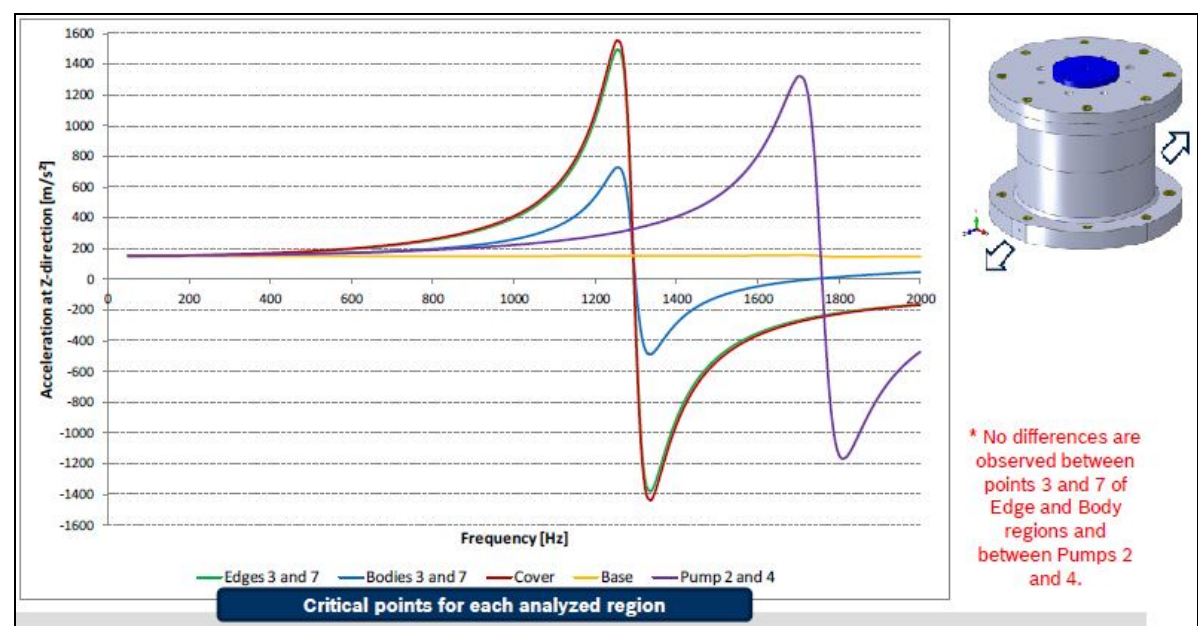

Figura 11 - Níveis de aceleração na direção $Z$

Tabela 4 - Máximas acelerações obtidas

\begin{tabular}{|c|c|c|c|c|c|c|}
\hline \multirow{2}{*}{ Region } & \multicolumn{2}{|c|}{ X-Direction } & \multicolumn{2}{c|}{ Y-Direction } & \multicolumn{2}{c|}{ Z-Direction } \\
\cline { 2 - 7 } & Point & $\begin{array}{c}\text { Maximum } \\
\text { Acceleration }\end{array}$ & Point & $\begin{array}{c}\text { Maximum } \\
\text { Acceleration }\end{array}$ & Point & $\begin{array}{c}\text { Maximum } \\
\text { Acceleration }\end{array}$ \\
\hline Edge & 1 and 5 & $\begin{array}{c}1496 \mathrm{~m} / \mathrm{s}^{2} \text { at } \\
1253 \mathrm{~Hz}\end{array}$ & 1 to 8 & $\begin{array}{c}253 \mathrm{~m} / \mathrm{s}^{2} \text { at } \\
2000 \mathrm{~Hz}\end{array}$ & 3 and 7 & $\begin{array}{c}1497 \mathrm{~m} / \mathrm{s}^{2} \text { at } \\
1253 \mathrm{~Hz}\end{array}$ \\
\hline Body & 1 and 5 & $\begin{array}{c}728 \mathrm{~m} / \mathrm{s}^{2} \text { at } \\
1253 \mathrm{~Hz}\end{array}$ & 1 to 8 & $\begin{array}{c}195 \mathrm{~m} / \mathrm{s}^{2} \text { at } \\
2000 \mathrm{~Hz}\end{array}$ & 3 and 7 & $\begin{array}{c}729 \mathrm{~m} / \mathrm{s}^{2} \text { at } \\
1253 \mathrm{~Hz}\end{array}$ \\
\hline Cover & - & $\begin{array}{c}1553 \mathrm{~m} / \mathrm{s}^{2} \text { at } \\
1253 \mathrm{~Hz}\end{array}$ & - & $\begin{array}{c}680 \mathrm{~m} / \mathrm{s}^{2} \text { at } \\
2000 \mathrm{~Hz}\end{array}$ & - & $\begin{array}{c}1553 \mathrm{~m} / \mathrm{s}^{2} \text { at } \\
1253 \mathrm{~Hz}\end{array}$ \\
\hline Base & - & $\begin{array}{c}156 \mathrm{~m} / \mathrm{s}^{2} \text { at } \\
1701 \mathrm{~Hz}\end{array}$ & - & $\begin{array}{c}150 \mathrm{~m} / \mathrm{s}^{2} \text { at } \\
2000 \mathrm{~Hz}\end{array}$ & - & $\begin{array}{c}156 \mathrm{~m} / \mathrm{s}^{2} \text { at } \\
1701 \mathrm{~Hz}\end{array}$ \\
\hline Pump & 1 and 3 & $\begin{array}{c}1321 \mathrm{~m} / \mathrm{s}^{2} \text { at } \\
1701 \mathrm{~Hz}\end{array}$ & 1 to 4 & $\begin{array}{c}150 \mathrm{~m} / \mathrm{s}^{2} \text { at } \\
2000 \mathrm{~Hz}\end{array}$ & 2 and 4 & $\begin{array}{c}1316 \mathrm{~m} / \mathrm{s}^{2} \text { at } \\
1701 \mathrm{~Hz}\end{array}$ \\
\hline
\end{tabular}

\section{CONSTRUÇÃO DO TANQUE}

Verificou-se que as frequências de ressonância obtidas pela análise de elementos finitos se apresentaram bem acima da máxima frequência do teste, ou seja, acima de $500 \mathrm{~Hz}$. No entanto notou-se a possibilidade de melhoria com a redução de massa na região da tampa e com o aumento da área de fixação do dispositivo central no fundo do tanque. O objetivo dessa melhoria seria o uso do tanque para testes em frequências mais elevadas. Esta avaliação será feita num trabalho futuro. 

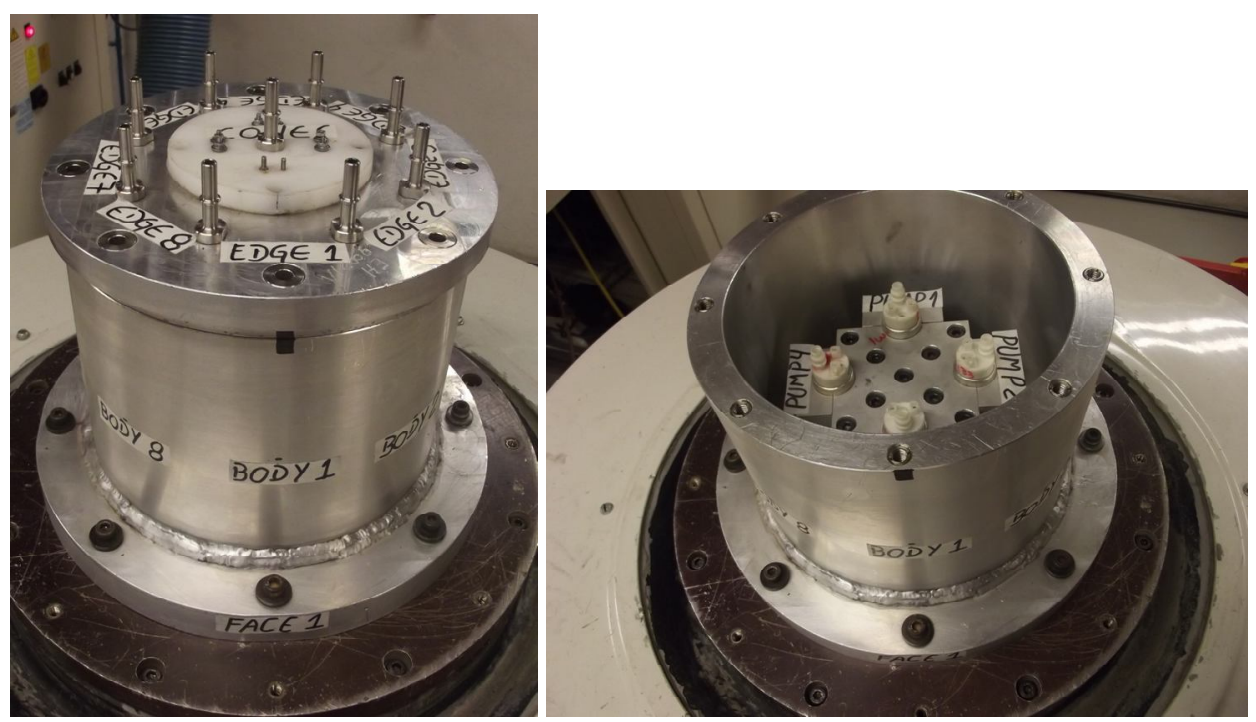

Figura 12 - Vistas do tanque construído

\section{ANÁLISE EXPERIMENTAL}

Após a usinagem do tanque foi realizada uma pesquisa de ressonância nos três eixos ortogonais para comparação, ajuste e validação dos parâmetros de simulação.

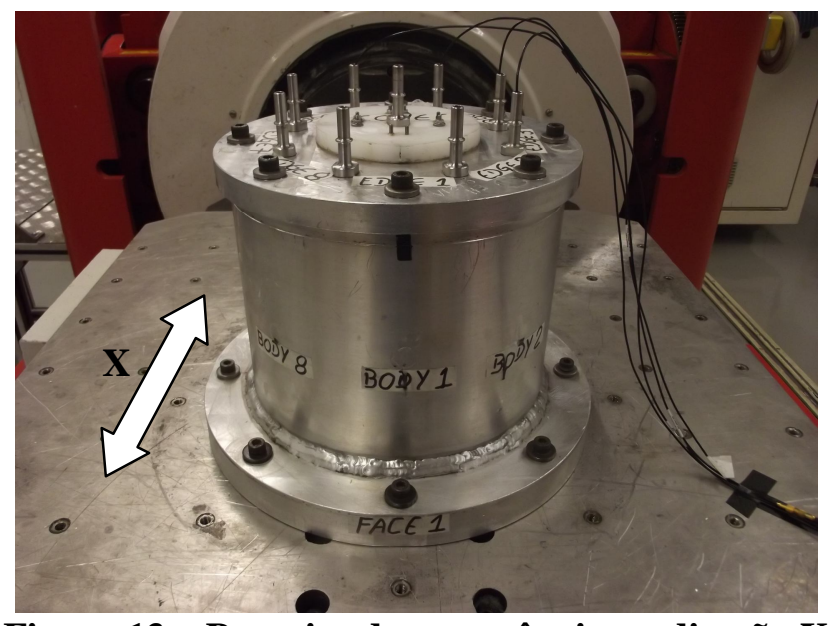

Figura 13 - Pesquisa de ressonância na direção $X$ 


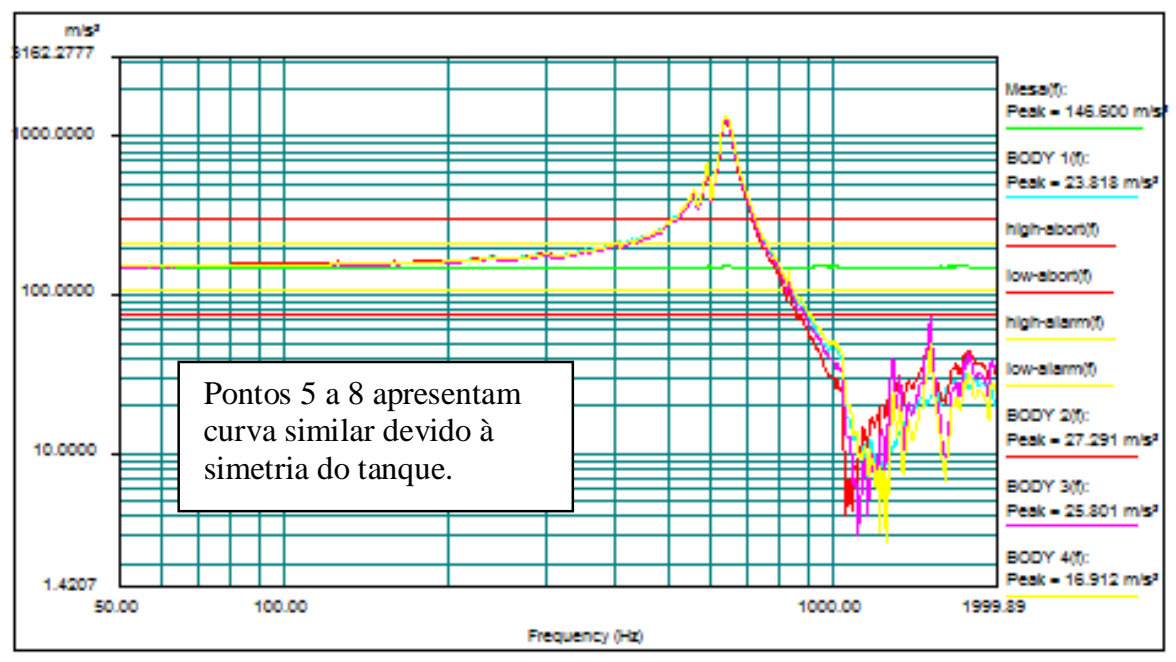

Figura 14 - Níveis de aceleração na direção X - "Body"

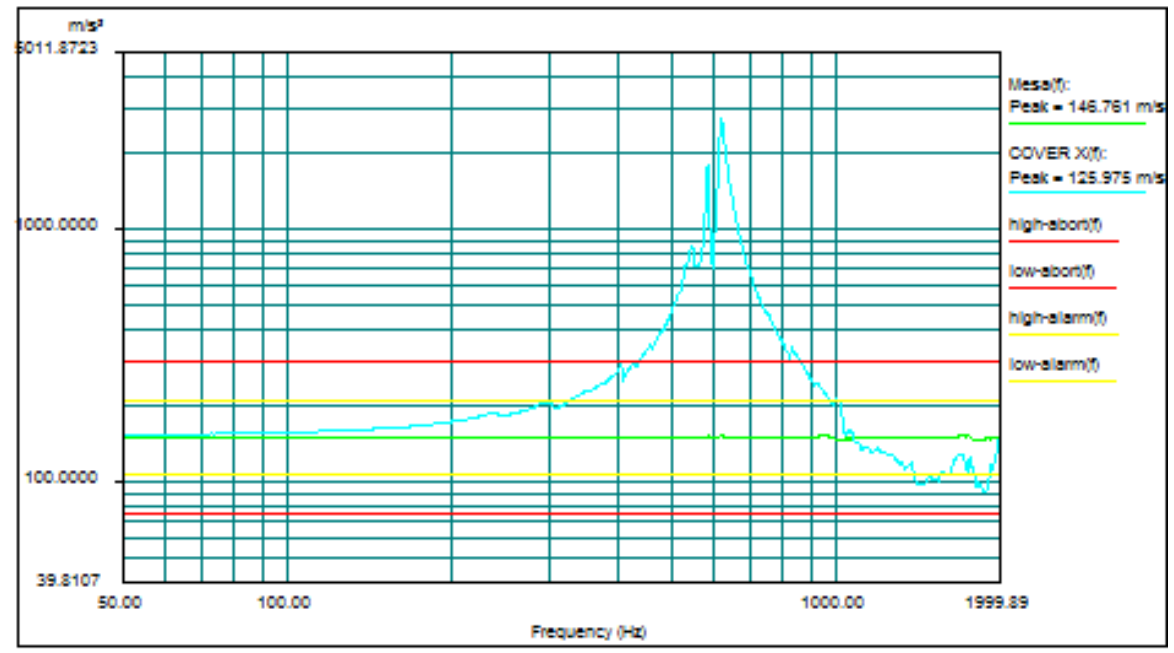

Figura 15 - Níveis de aceleração na direção X - "Cover"

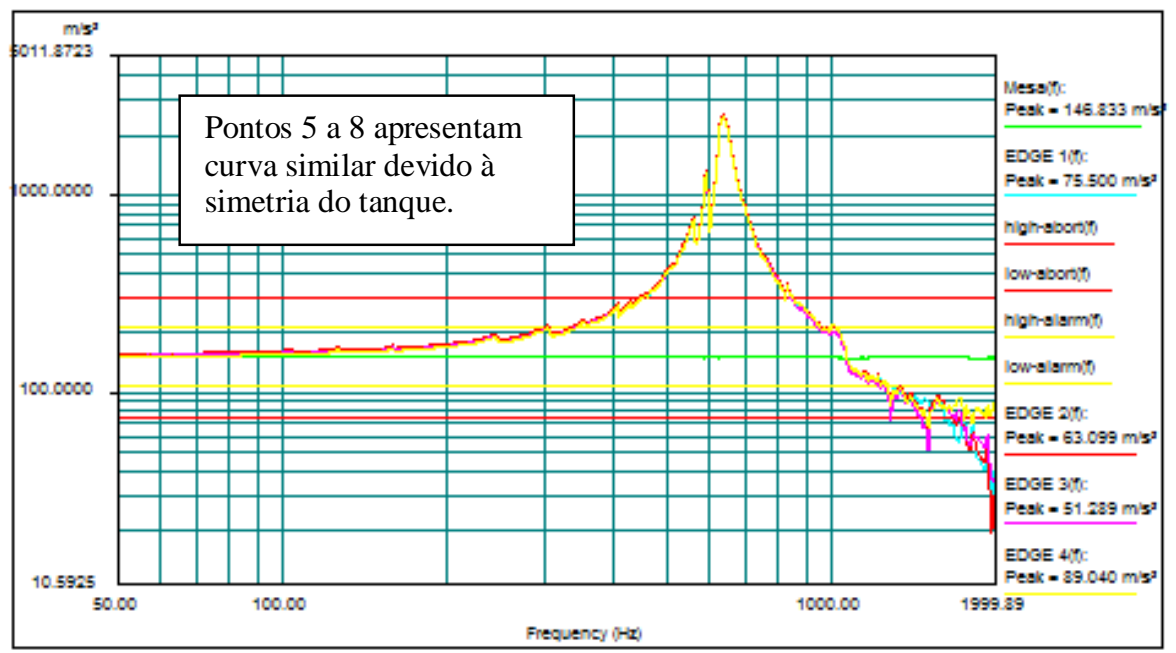

Figura 16 - Níveis de aceleração na direção X - "Edge" 


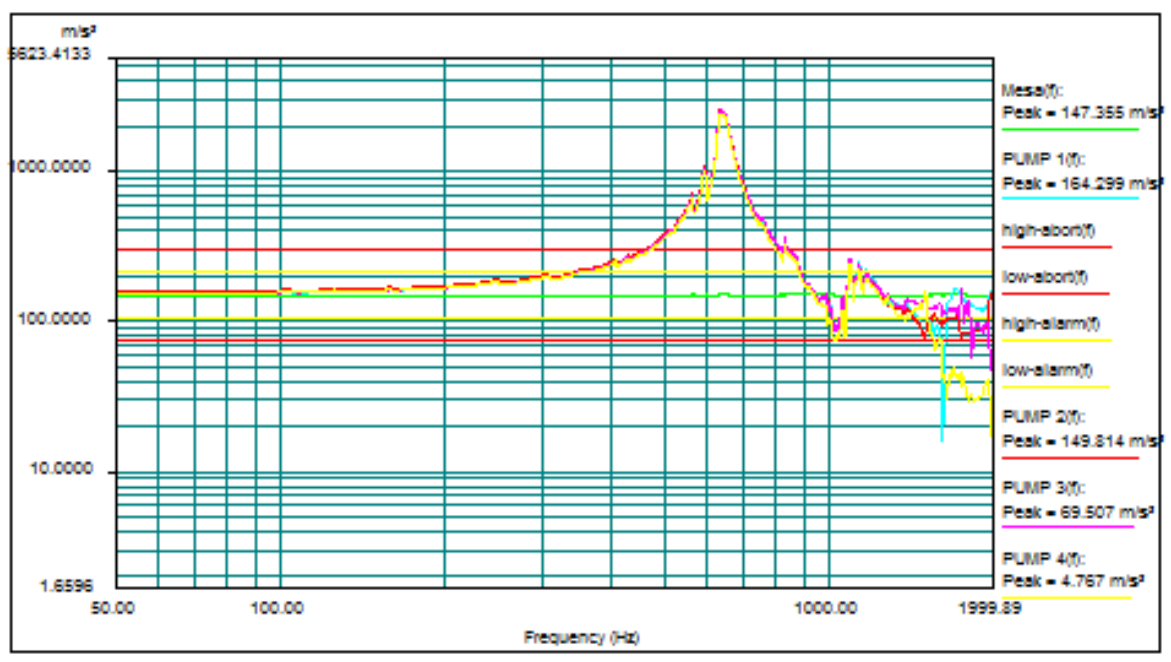

Figura 17 - Níveis de aceleração na direção X - "Pump"

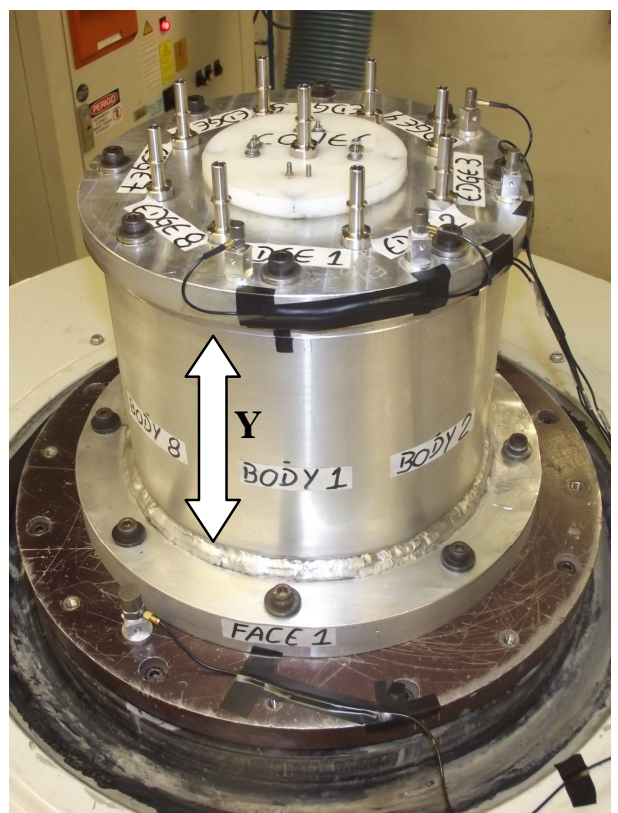

Figura 18 - Pesquisa de ressonância na direção Y 


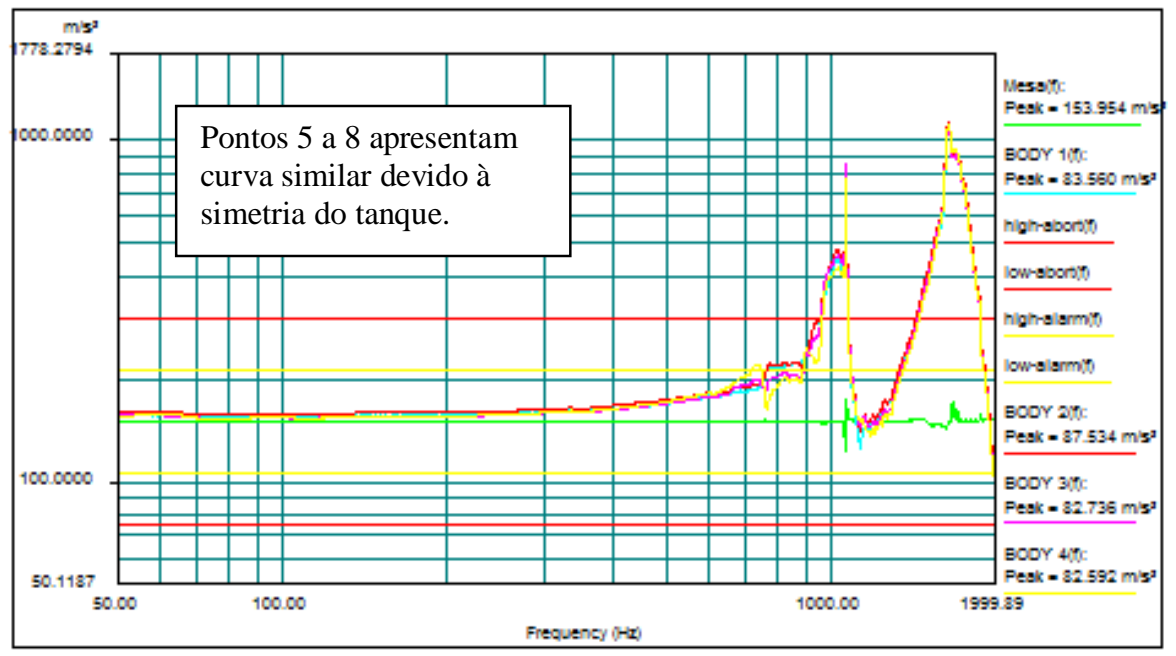

Figura 19 - Níveis de aceleração na direção Y - "Body"

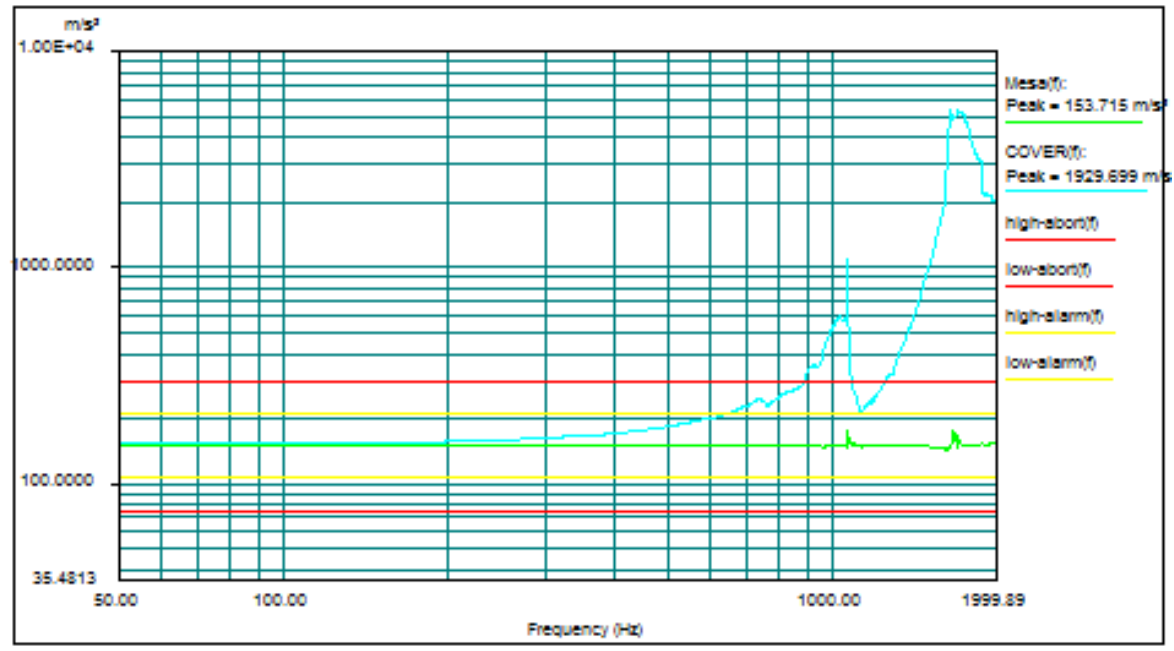

Figura 20 - Níveis de aceleração na direção Y - "Cover"

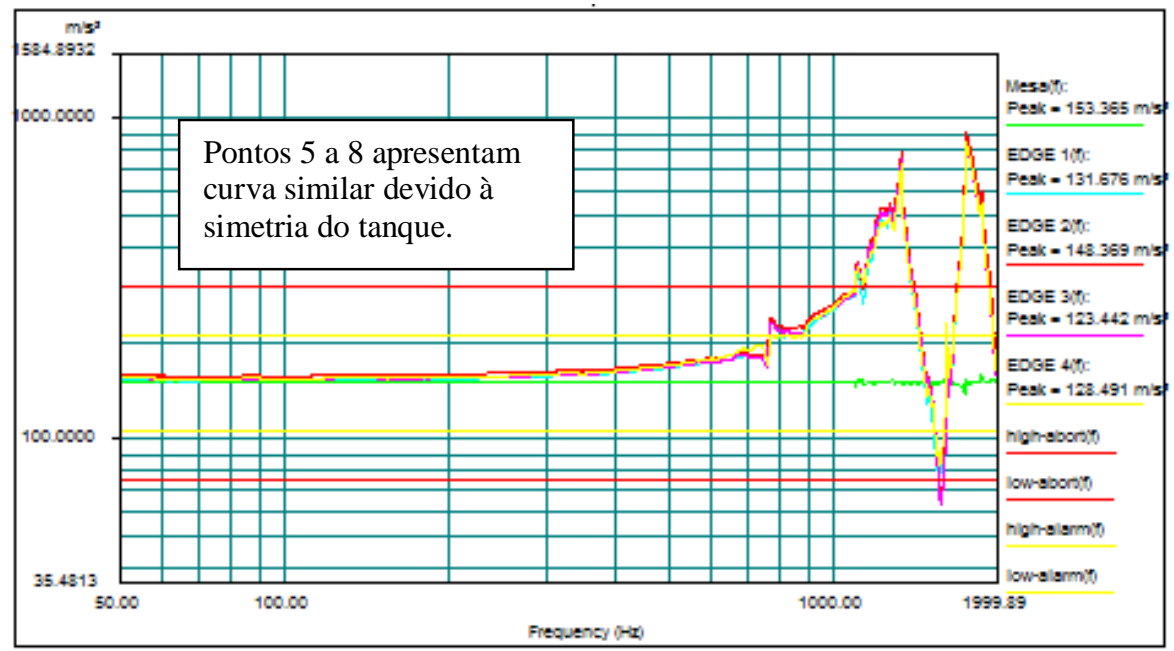

Figura 21 - Níveis de aceleração na direção Y - "Edge" 


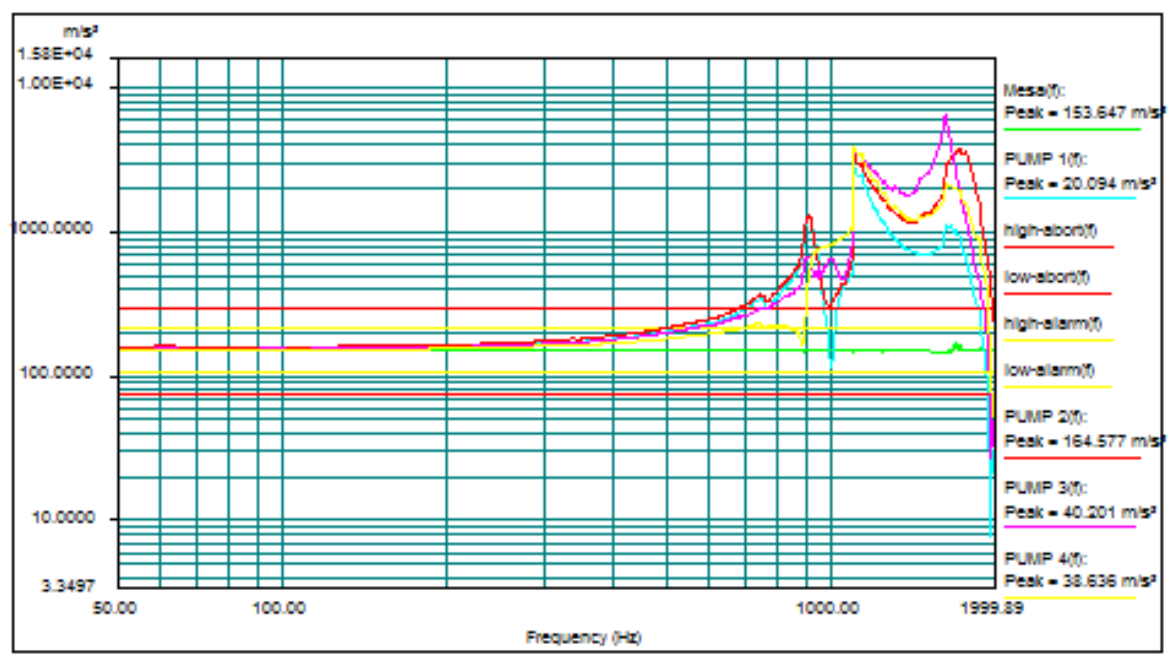

Figura 22 - Níveis de aceleração na direção Y - "Pump"

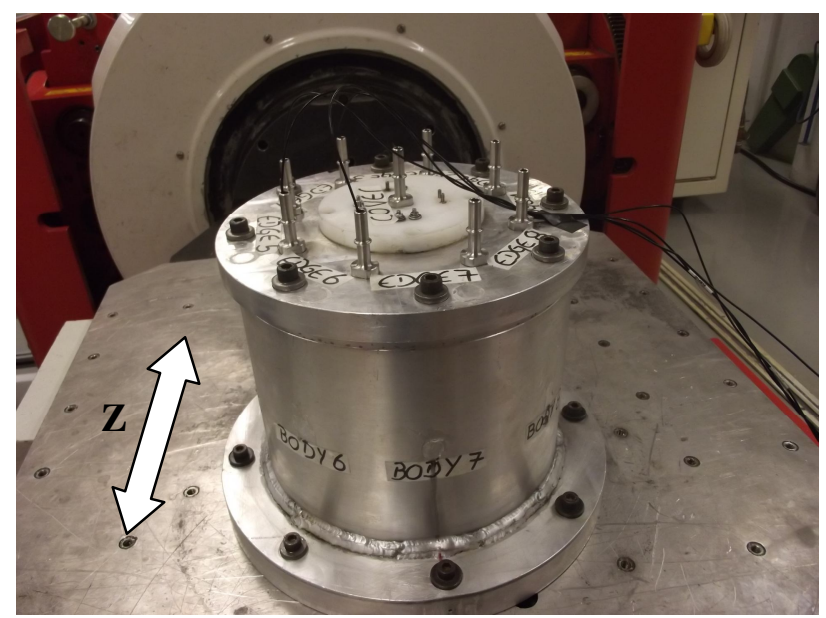

Figura 23 - Pesquisa de ressonância na direção Z

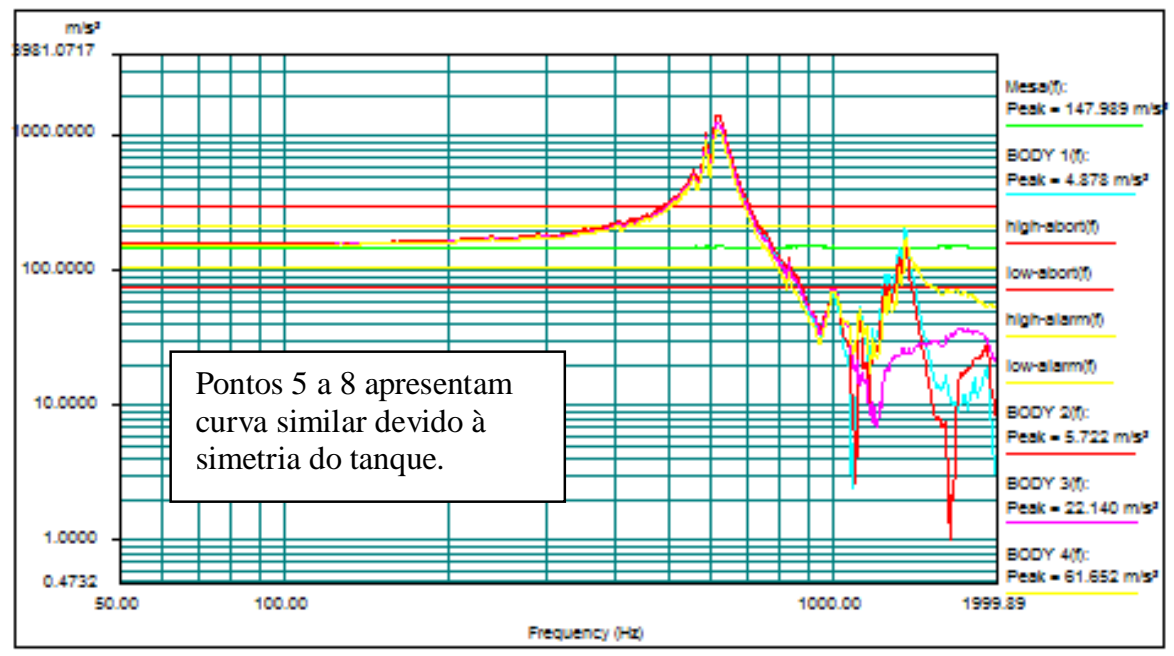

Figura 24 - Níveis de aceleração na direção Z - "Body" 


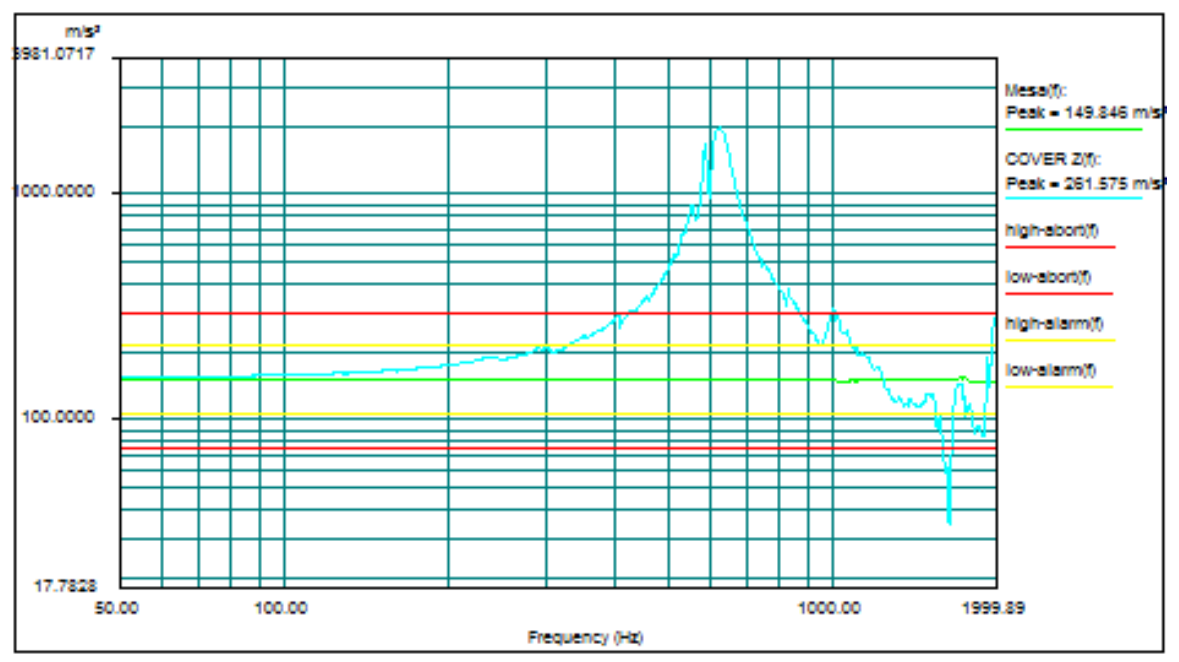

Figura 25 - Níveis de aceleração na direção Z - “Cover”

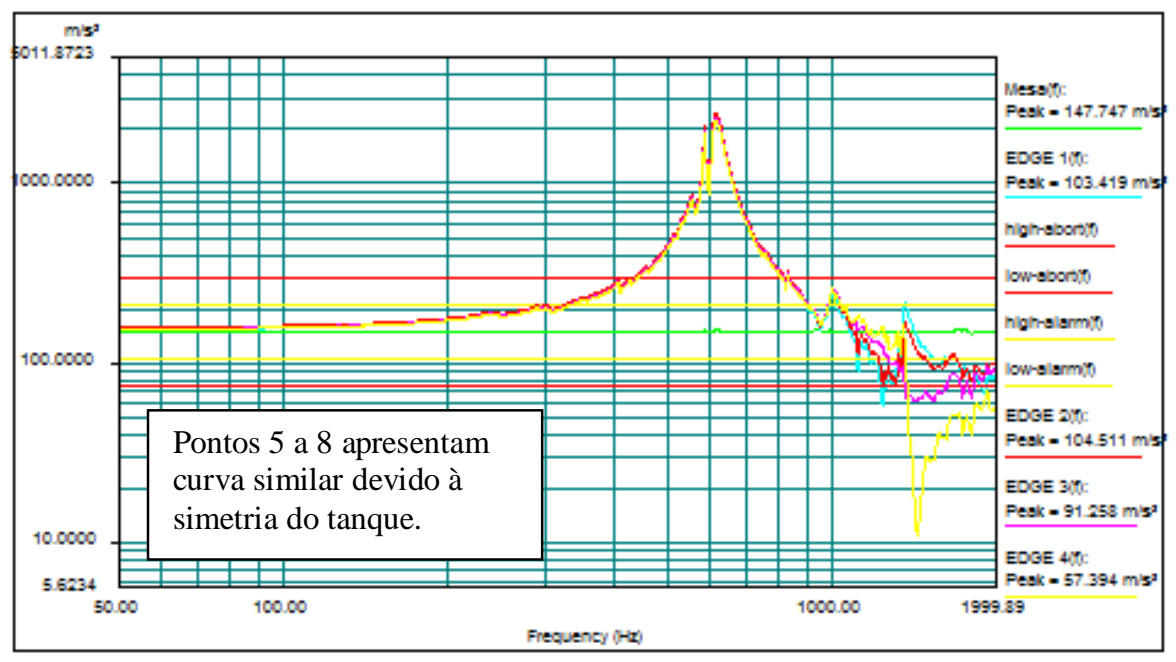

Figura 26 - Níveis de aceleração na direção Z - "Edge"

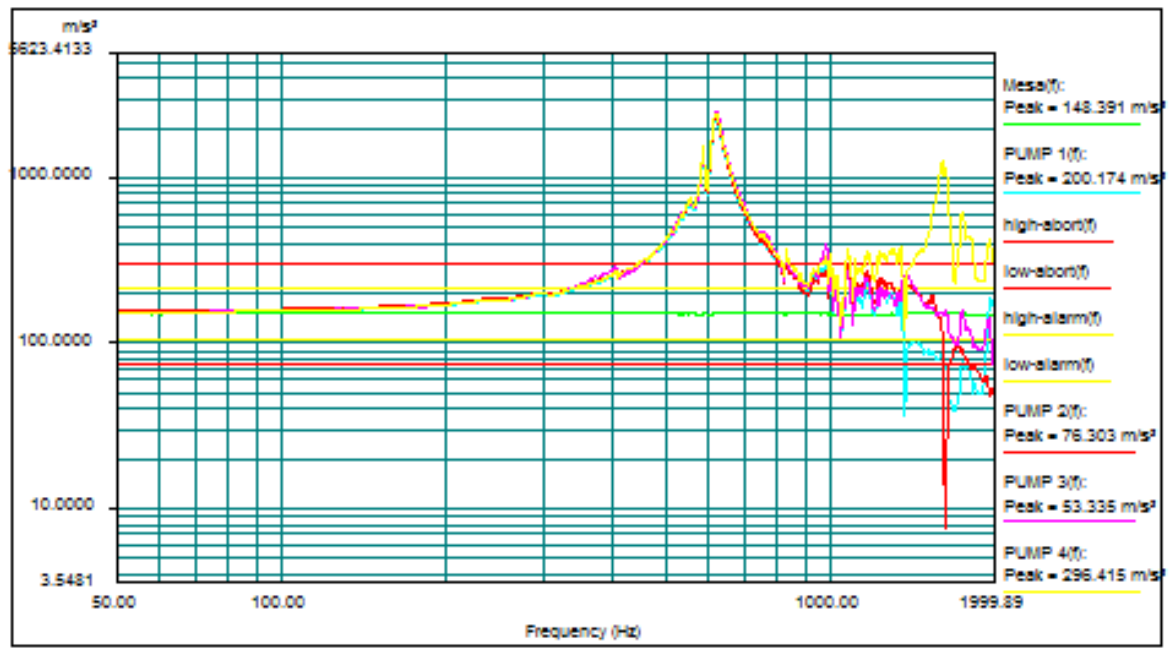

Figura 27 - Níveis de aceleração na direção Z - "Pump” 
Tabela 5 - Máxima aceleração obtida experimentalmente

\begin{tabular}{|c|c|c|c|c|c|c|c|}
\hline \multirow[b]{2}{*}{ Region } & \multirow[b]{2}{*}{ Point } & \multicolumn{2}{|c|}{ X-Direction } & \multicolumn{2}{|c|}{ Y-Direction } & \multicolumn{2}{|c|}{ Z-Direction } \\
\hline & & $\begin{array}{l}\text { Freq. } \\
{[\mathrm{Hz}]}\end{array}$ & $\begin{array}{l}\text { Max. } \\
\text { Acc. } \\
{\left[\mathrm{m} / \mathrm{s}^{2}\right]}\end{array}$ & $\begin{array}{l}\text { Freq. } \\
{[\mathrm{Hz}]}\end{array}$ & $\begin{array}{l}\text { Max. } \\
\text { Acc. } \\
{\left[\mathrm{m} / \mathrm{s}^{2}\right]}\end{array}$ & $\begin{array}{l}\text { Freq. } \\
{[\mathrm{Hz}]}\end{array}$ & $\begin{array}{l}\text { Max. } \\
\text { Acc. } \\
{\left[\mathrm{m} / \mathrm{s}^{2}\right]}\end{array}$ \\
\hline \multirow{8}{*}{ Edge } & 1 & 635,4 & 2483 & 1330,6 & 757 & 612,8 & 2350 \\
\hline & 2 & 635,4 & 2483 & 1330,6 & 806 & 612,8 & 2387 \\
\hline & 3 & 635,4 & 2403 & 1330,6 & 764 & 615,1 & 2274 \\
\hline & 4 & 635,4 & 2407 & 1330,6 & 731 & 612,8 & 2177 \\
\hline & 5 & 635,4 & 2406 & 1103,1 & 410 & 615,1 & 2149 \\
\hline & 6 & 635,4 & 2450 & 1103,1 & 432 & 615,1 & 2293 \\
\hline & 7 & 637,6 & 2359 & 1103,1 & 444 & 615,1 & 2609 \\
\hline & 8 & 637,6 & 2358 & 1103,1 & 507 & 615,1 & 2435 \\
\hline \multirow{8}{*}{ Body } & 1 & 639,9 & 1305 & 1064,0 & 763 & 615,1 & 1383 \\
\hline & 2 & 639,9 & 1243 & 1064,0 & 823 & 617,3 & 1405 \\
\hline & 3 & 639,9 & 1276 & 1064,0 & 855 & 615,1 & 1234 \\
\hline & 4 & 639,9 & 1335 & 1064,0 & 778 & 615,1 & 1086 \\
\hline & 5 & 639,9 & 1344 & 1064,0 & 714 & 621,8 & 995 \\
\hline & 6 & 639,9 & 1252 & 1064,0 & 679 & 621,8 & 1051 \\
\hline & 7 & 642,3 & 1276 & 1064,0 & 657 & 619,5 & 1176 \\
\hline & 8 & 639,9 & 1250 & 1064,0 & 745 & 619,5 & 1348 \\
\hline Cover & - & 617,3 & 2699 & 1064,0 & 1095 & 617,3 & 1943 \\
\hline \multirow{4}{*}{ Pump } & 1 & 637,6 & 2496 & 1103,1 & 3562 & 617,3 & 2262 \\
\hline & 2 & 637,6 & 2523 & 1103,1 & 4293 & 617,3 & 2352 \\
\hline & 3 & 637,6 & 2509 & 1103,1 & 4682 & 617,3 & 2501 \\
\hline & 4 & 637,6 & 2393 & 1103,1 & 4702 & 617,3 & 2409 \\
\hline
\end{tabular}

Após a pesquisa de ressonância em shaker verificou-se que as frequências e amplitudes ficaram bem abaixo dos valores de frequência simuladas. A comparação direta ficou prejudicada devido à alteração feita na geometria no momento da construção do tanque.

\section{FEA - AJUSTE DE MODELO}

Com o intuito de se ajustar o modelo de simulação para condizer com os valores experimentais, um novo modelo foi feito e uma nova simulação foi realizada. Para essa nova simulação utilizou-se o mesmo coeficiente de amortecimento da simulação anterior, porém mudanças nas condições de contorno foram realizadas, como por exemplo a fixação do tanque no shaker pelos parafusos e não mais pela base. 

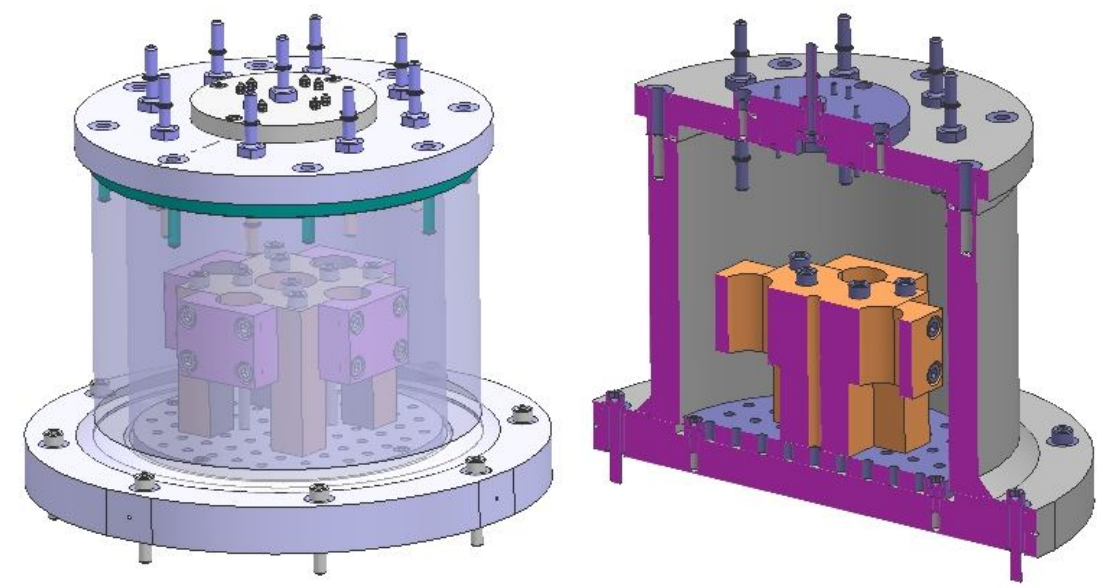

Figura 28 - Novo modelo do tanque de teste baseado no tanque construído

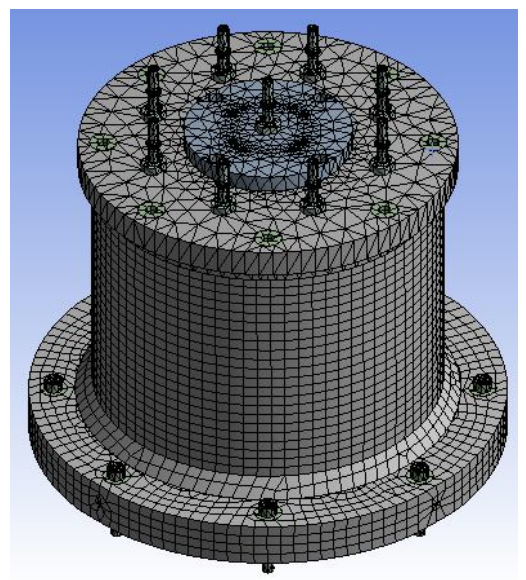

Figura 29 - Malha com 205.529 elementos

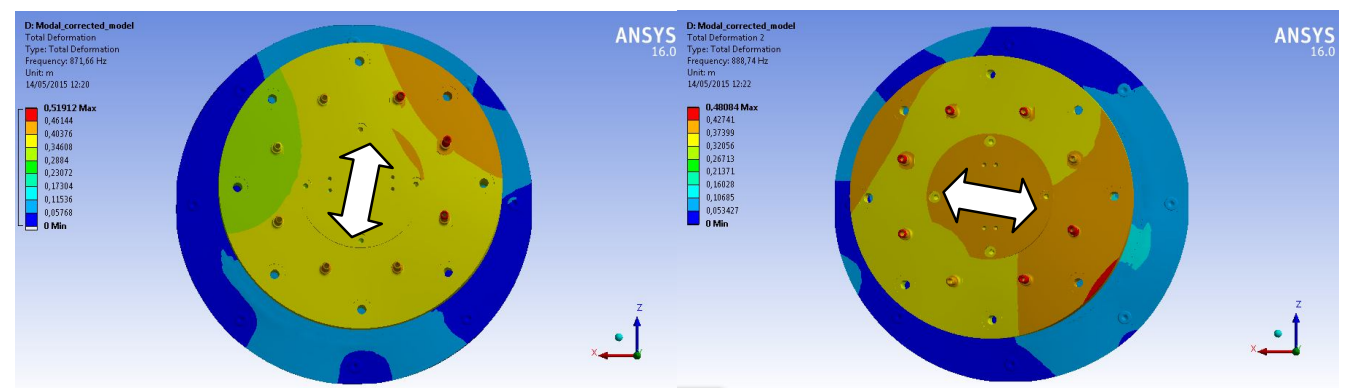

Figura 30 - Frequências naturais do $1^{\circ}$ e $2^{\circ}$ modo: 871,6 Hz e 888,74Hz respectivamente

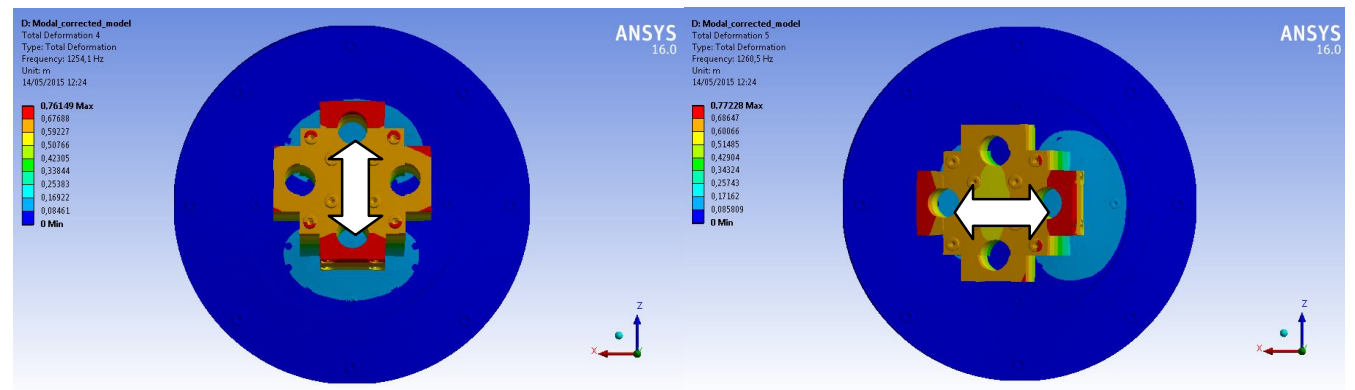

Figura 31 - Frequências naturais do $4^{\circ}$ e $5^{\circ}$ modo: $1254,1 \mathrm{~Hz}$ e 1260,5Hz respectivamente 
Mais uma vez foram levantadas, através da análise harmônica, as acelerações em pontos estratégicos quando aplicada na base uma aceleração constante de $150 \mathrm{~m} / \mathrm{s}^{2}$ variando de 50 a $2000 \mathrm{~Hz}$.

Obtiveram-se os seguintes níveis de aceleração:

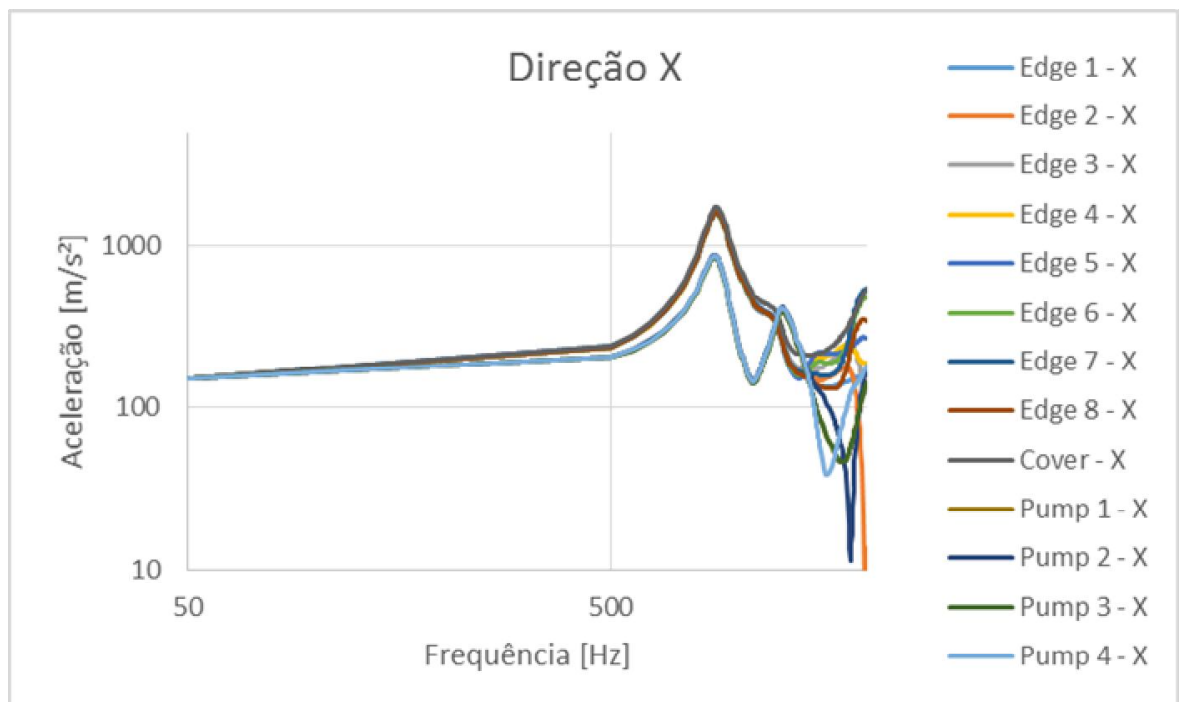

Figura 32 - Níveis de na direção $X$

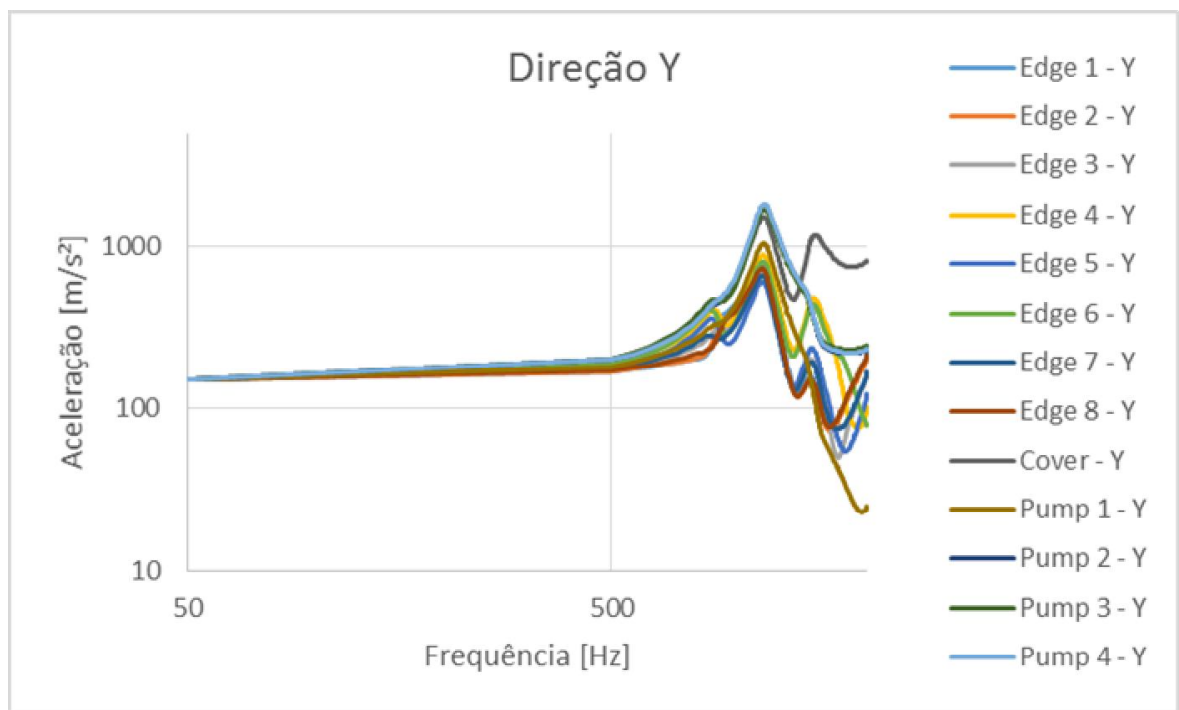

Figura 33 - Níveis de na direção Y 


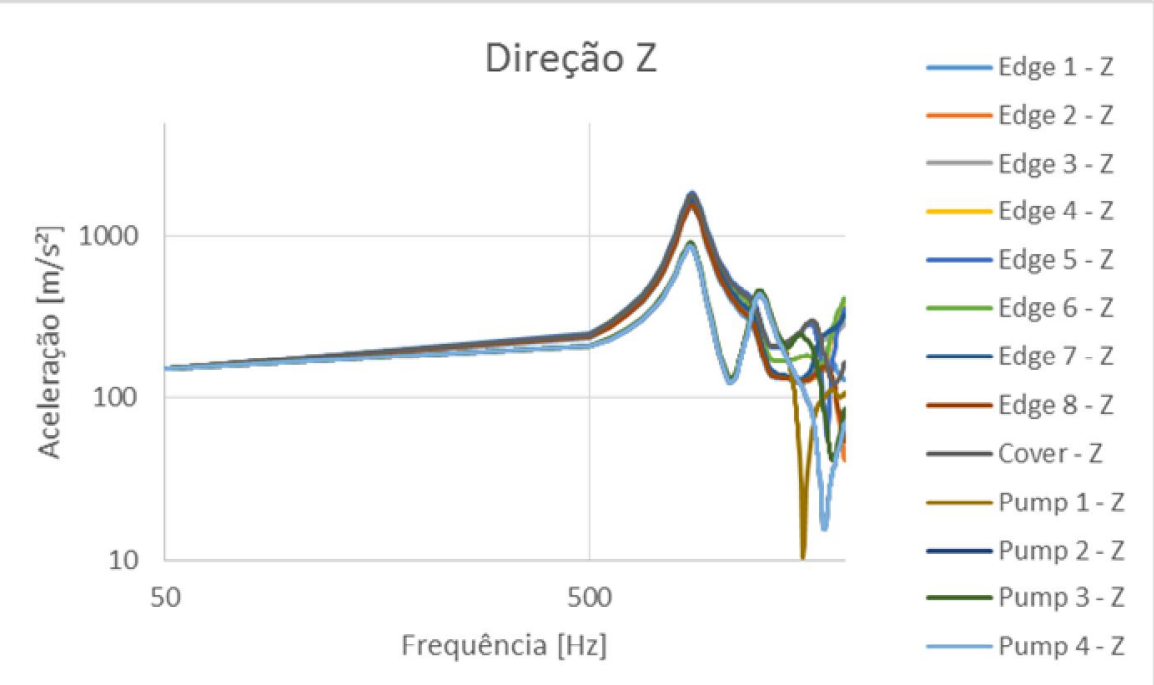

Figura 34 - Níveis de na direção Z

Tabela 6 - Máximas acelerações obtidas

\begin{tabular}{|c|c|c|c|c|c|c|}
\hline \multirow{2}{*}{ Region } & \multicolumn{2}{|c|}{ X-Direction } & \multicolumn{2}{c|}{ Y-Direction } & \multicolumn{2}{c|}{ Z-Direction } \\
\cline { 2 - 7 } & Point & $\begin{array}{c}\text { Maximum } \\
\text { Acceleration }\end{array}$ & Point & $\begin{array}{c}\text { Maximum } \\
\text { Acceleration }\end{array}$ & Point & $\begin{array}{c}\text { Maximum } \\
\text { Acceleration }\end{array}$ \\
\hline Edge & 1 & $\begin{array}{c}1641 \mathrm{~m} / \mathrm{s}^{2} \text { at } \\
885 \mathrm{~Hz}\end{array}$ & 4 & $\begin{array}{c}885 \mathrm{~m} / \mathrm{s}^{2} \text { at } \\
1138 \mathrm{~Hz}\end{array}$ & 5 & $\begin{array}{c}1850 \mathrm{~m} / \mathrm{s}^{2} \text { at } \\
872 \mathrm{~Hz}\end{array}$ \\
\hline Cover & - & $\begin{array}{c}1738 \mathrm{~m} / \mathrm{s}^{2} \text { at } \\
885 \mathrm{~Hz}\end{array}$ & - & $\begin{array}{c}1532 \mathrm{~m} / \mathrm{s}^{2} \text { at } \\
1140 \mathrm{~Hz}\end{array}$ & - & $\begin{array}{c}1803 \mathrm{~m} / \mathrm{s}^{2} \text { at } \\
872 \mathrm{~Hz}\end{array}$ \\
\hline Pump & 2 & $\begin{array}{c}877 \mathrm{~m} / \mathrm{s}^{2} \text { at } \\
879 \mathrm{~Hz}\end{array}$ & 4 & $\begin{array}{c}1839 \mathrm{~m} / \mathrm{s}^{2} \text { at } \\
1146 \mathrm{~Hz}\end{array}$ & 2 and 4 & $\begin{array}{c}906,3 \mathrm{~m} / \mathrm{s}^{2} \text { at } \\
864 \mathrm{~Hz}\end{array}$ \\
\hline
\end{tabular}

As tabelas 7, 8 e 9 apresentam um comparativo dos resultados obtidos.

\section{Tabela 7 - Máximas acelerações obtidas em X}

\begin{tabular}{|c|c|c|}
\hline \multirow{2}{*}{ Region } & \multicolumn{2}{|c|}{ X-Direction } \\
\cline { 2 - 3 } & Experiment & 2nd simulation \\
\hline Edge & $2483 \mathrm{~m} / \mathrm{s}^{2}$ at $635 \mathrm{~Hz}$ & $1641 \mathrm{~m} / \mathrm{s}^{2}$ at $885 \mathrm{~Hz}$ \\
\hline Body & $1344 \mathrm{~m} / \mathrm{s}^{2}$ at $640 \mathrm{~Hz}$ & - \\
\hline Cover & $2699 \mathrm{~m} / \mathrm{s}^{2}$ at $617 \mathrm{~Hz}$ & $1738 \mathrm{~m} / \mathrm{s}^{2}$ at $885 \mathrm{~Hz}$ \\
\hline Pump & $2523 \mathrm{~m} / \mathrm{s}^{2}$ at $638 \mathrm{~Hz}$ & $1085 \mathrm{~m} / \mathrm{s}^{2}$ at $880 \mathrm{~Hz}$ \\
\hline
\end{tabular}

Tabela 8 - Máximas acelerações obtidas em Y

\begin{tabular}{|c|c|c|}
\hline \multirow{2}{*}{ Region } & \multicolumn{2}{|c|}{ Y-Direction } \\
\cline { 2 - 3 } & Experiment & 2nd simulation \\
\hline Edge & $806 \mathrm{~m} / \mathrm{s}^{2}$ at $1331 \mathrm{~Hz}$ & $885 \mathrm{~m} / \mathrm{s}^{2}$ at $1138 \mathrm{~Hz}$ \\
\hline Body & $855 \mathrm{~m} / \mathrm{s}^{2}$ at $1064 \mathrm{~Hz}$ & - \\
\hline Cover & $1095 \mathrm{~m} / \mathrm{s}^{2}$ at $1064 \mathrm{~Hz}$ & $1532 \mathrm{~m} / \mathrm{s}^{2}$ at $1140 \mathrm{~Hz}$ \\
\hline Pump & $4702 \mathrm{~m} / \mathrm{s}^{2}$ at $1103 \mathrm{~Hz}$ & $1905 \mathrm{~m} / \mathrm{s}^{2}$ at $1146 \mathrm{~Hz}$ \\
\hline
\end{tabular}


Tabela 9 - Máximas acelerações obtidas em Z

\begin{tabular}{|c|c|c|}
\hline \multirow{2}{*}{ Region } & \multicolumn{2}{|c|}{ Z-Direction } \\
\cline { 2 - 3 } & Experiment & 2nd simulation \\
\hline Edge & $2609 \mathrm{~m} / \mathrm{s}^{2}$ at $615 \mathrm{~Hz}$ & $1850 \mathrm{~m} / \mathrm{s}^{2}$ at $872 \mathrm{~Hz}$ \\
\hline Body & $1405 \mathrm{~m} / \mathrm{s}^{2}$ at $617,3 \mathrm{~Hz}$ & - \\
\hline Cover & $1943 \mathrm{~m} / \mathrm{s}^{2}$ at $617 \mathrm{~Hz}$ & $1803 \mathrm{~m} / \mathrm{s}^{2}$ at $872 \mathrm{~Hz}$ \\
\hline Pump & $2501 \mathrm{~m} / \mathrm{s}^{2}$ at $617 \mathrm{~Hz}$ & $1083 \mathrm{~m} / \mathrm{s}^{2}$ at $867 \mathrm{~Hz}$ \\
\hline
\end{tabular}

\section{CONCLUSÃO}

Devido à modificação do tanque em relação ao design original não foi possível a comparação direta com os resultados do experimento e da segunda simulação. Comparando-se então os valores desses dois últimos, nota-se um erro médio de $27 \%$ para as frequências naturais e de $25 \%$ para as amplitudes. Esso erro provavelmente se deve às condições de contorno utilizadas e que não representam totalmente a realidade. Devemos levar em conta que as análises modais e harmônicas consideram que todos os contatos envolvidos na análise são do tipo linear (bounded), ou seja, não há deslocamento relativo entre os componentes da montagem. Outro fator de erro se deve ao coeficiente de amortecimento utilizado na análise.

Novas análises e mudanças podem ainda serem feitas no intuito de se conseguir valores mais próximos dos valores experimentais, por exemplo, alteração do coeficiente de amortecimento.

Como trabalhos futuros, sugere-se a inclusão do fluído de teste tanto na simulação como na pesquisa de ressonância em laboratório, onde o objetivo final é termos um modelo para o dispositivo que nos permita via simulação atingir um nível de correspondência com o shaker acima de $90 \%$ tanto para frequências quanto amplitudes.

\section{REFERÊNCIAS}

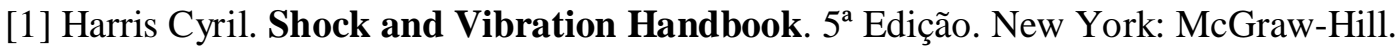
[2] Bruel \& Kjaer. Shaker Control User Guide, Revisão 8.0, página 511, 2009. 